\title{
OPEM
}

www.opem.org

Oriental Pharmacy and Experimental Medicine 2008 8(4), 365-373

DOI 10.3742/OPEM.2008.8.4.365

\section{Nootropic Potential of Murraya koenigii leaves in Rats}

\author{
Mani Vasudevan ${ }^{1, *}$, Milind Parle ${ }^{2}$, Singaravel Sengottuvelu ${ }^{1}$ and Thulasimani Shanmugapriya ${ }^{3}$ \\ ${ }^{1}$ Pharmacology Division, Nandha College of Pharmacy, Koorapalayam Pirivu, Pitchandampalayam, Erode-District., \\ Tamilnadu-638052, India; ${ }^{2}$ Pharmacology Division, Department of Pharmaceutical Sciences, Post Box-38, Guru \\ Jambheshwar University of Science and Technology, Hisar, Haryana -125001, India; ${ }^{3}$ Department of Food and \\ Nutrition, Vellalar College for Women, Erode-District, Tamilnadu-38009, India.
}

Received for publication August 27, 2007; accepted April 08, 2008

\begin{abstract}
SUMMARY
Murraya koenigii leaves commonly known as 'curry patta' are routinely added to Indian gravy and vegetarian dishes by south Indian as a favourate condiment. The present study was undertaken to investigate the effects of Murraya koenigii leaves (MKL) on memory in rats. Elevated plus-maze and Hebb-Williams maze served as the exteroceptive behavioral models for testing memory. Diazepam-, scopolamine- and ageing-induced amnesia served as the interoceptive behavioral models. MKL fed orally to various groups of young and aged rats with diet containing 2, 4 and 8\% w/w of MKL for 30 days consecutively were investigated. The MKL diets produced a significant dose-dependent improvement in memory scores of young and aged rats and significantly reduced the amnesia induced by scopolamine $(0.4 \mathrm{mg} / \mathrm{kg}$, i.p.) and diazepam $(1 \mathrm{mg} / \mathrm{kg}$, i.p.). Therefore, it would be worthwhile to specifically investigate the therapeutic potential of MKL in the management of dementia patients.
\end{abstract}

Key words: Amnesia; Memory; Murraya koenigii

\section{INTRODUCTION}

Murraya koenigii (Linn.) Spreng (Family: Rutaceae), commonly known as 'curry patta' in Hindi is popular as a spice and condiment among the South Indians. The fresh leaves of Murraya koenigii (MKL) are traditionally added to Indian gravy and other vegetables for the delicious taste they impart to various South Indian dishes. Ayurvedic literature as well as recent studies highlights the potential of MKL as an antidiabetic agent (Yadav et al., 2002;

*Correspondence: Mani Vasudevan, Pharmacology Division, Nandha College of Pharmacy, Koorapalayam Pirivu, Pitchandampalayam, Erode-District., Tamilnadu638052, India. Tel: +919486518703; E-mail: vasumpharmacol @yahoo.co.uk
Adebajo et al., 2004, 2006; Kesari et al., 2005). Leaf extract of Murraya koenigii have also been reported to posses antifungal, antineoplastic, nitric oxide scavenging and antioxidant activities (Das et al., 1965; Khan et al., 1996a; Chakrabarty et al., 1997; Khan et al., 1997; Ramsewak, et al., 1999; Tachibana et al., 2001; Baliga et al., 2003). Anti-oxidant, Antitumor, Anti-microbial and Anti-diabetic actives have been reported for some carbazole alkaloids, which were identified as the major compounds in Murraya koenigii leaves (Tachibana et al., 2001; Adebajo et al., 2004, 2006; Ito et al., 2006).

Dementia is a mental disorder characterized by loss of intellectual ability sufficiently severe as to interfere with one's occupational or social activities. Dementia is of several types and it invariably 
involves impairment of memory. The most common cause of dementia is Alzheimer's disease, which is a progressive neurodegenerative disorder associated with loss of neurons in distinct brain areas (Parle $e t$ al., 2004). Nootropics represent a new class of psychotropic agents with selective facilitatory effect on integrative functions of the central nervous system, particularly on intellectual performance, learning capacity and memory (Chintawar et al., 2002). Nootropic agents such as piracetam, aniracetam and choline esterase inhibitors like donepezil are being used for improving memory, mood and behavior, but the resulting side effects associated with these agents have made their applicability limited (Bhattacharya et al., 1993; Rogers et al., 1998). Since the allopathic system of medicine is yet to provide a radical cure for memory deficit, it is worthwhile to explore the utility of traditional medicines. In the light of this, the present study was undertaken to investigate the influence of Murraya koenigii leaves on memory of rats.

\section{MATERIALS AND METHODS}

\section{Plant material}

The fresh leaves of Murraya koenigii were collected during the month of October, 2004 from the outskirts of Erode city situated in the state of Tamil Nadu (India). The plant material was authenticated by Dr. H.B. Singh, The Head, Raw Materials, Herbarium and Museum division, National Institute of Science Communication and Information Resources (NISCAIR), New Delhi, India and a voucher specimen (NISCAIR/RHM/549/23) was deposited in this herbarium. The collected leaves were dried under shade and powdered to give MKL which was preserved in airtight container until needed for pharmacological investigations. Different daily doses were prepared by separately mixing certain amounts $(2,4 \& 8 \% \mathrm{w} / \mathrm{w})$ of MKL powder with wheat flour to give a total of $3 \mathrm{~g} / \mathrm{animal} /$ day. The concentrations of MKL in diet were determined on the basis of pilot study and literature reports (Khan et al., 1996a, 1996b; Yadav et al., 2002).

\section{Experimental animals}

All the experiments were carried out using male, Wistar rats procured from the disease-free small animal house of CCS Haryana Agricultural University, Hisar (Haryana), India. Young (3 - 4 months old) rats weighing around $150 \mathrm{~g}$ and aged (12-15 months old) rats weighing around $250 \mathrm{~g}$ were used in the present study. The animals had free access to food and water, and they were housed in a natural (12 h each) light-dark cycle. Food given to animals consisted of wheat flour kneaded with water and mixed with a small amount of refined vegetable oil. The animals were acclimatized for at least 5 days to the laboratory conditions before behavioral experiments. Experiments were carried out between $0900 \mathrm{~h}$ and $1800 \mathrm{~h}$. The experimental protocol was approved by the Institutional Animal Ethics Committee (IAEC) and the care of laboratory animals was taken as per the guidance of CPCSEA, Ministry of Forests and Environment, Government of India (registration number 0436).

\section{Chemicals}

The drugs used in this study were obtained from following drug houses. Scopolamine hydrobromide (Sigma-Aldrich, USA), diazepam injection (Calmpose ${ }^{\circledR}$, Ranbaxy, India) and piracetam (UCB India Ltd., India).

\section{Drug treatment}

In the present investigation, the rats were divided into different groups $(n=6)$ for investigations using various interoceptive as well as exteroceptive memory models. The daily diet doses $(2,4 \& 8 \% \mathrm{w} / \mathrm{w})$ of MKL were fed to young and aged rats of different groups for 30 days. These rats were exposed to the training session using elevated plus maze or HebbWilliams maze on the $30^{\text {th }}$ day 90 min after the last feed. Retention (memory) of the learned task was recorded after $24 \mathrm{~h}$ i.e. on $31^{\text {st }}$ day (Dhingra et al., 
2003; Parle and Dhingra, 2003). Amnesia was induced in separate groups (interoceptive model) of young rats by scopolamine $(0.4 \mathrm{mg} / \mathrm{kg}$, i.p.) or diazepam $\left(1 \mathrm{mg} / \mathrm{kg}\right.$, i.p.) on $30^{\text {th }}$ day after $90 \mathrm{~min}$ of the last feed. The animals were exposed to the training session (on $30^{\text {th }}$ day) after 45 min of scopolamine or diazepam injection. The retention (memory) was measured after $24 \mathrm{~h}$ (on $31^{\text {st }}$ day). Piracetam (400 $\mathrm{mg} / \mathrm{kg}$, i.p.), an established nootropic agent was injected for seven days to positive control groups of animals. The control group animals were fed with normal diet of wheat flour ( $3 \mathrm{~g} / \mathrm{animal} /$ day) for 30 days.

\section{Elevated plus-maze}

Elevated plus-maze served as the exteroceptive behavioral model to evaluate memory in rats. The procedure, technique and end point for testing memory was followed as per the parameters described by the investigators working in the area of psychopharmacology (Itoh et al., 1990; Reddy and Kulkarni, 1998; Parle et al., 2005). The elevated plus maze apparatus for rats consisted of a central platform $\left(10 \mathrm{~cm}^{2}\right)$ connected to two open arms $(50 \mathrm{~cm}$ $\times 10 \mathrm{~cm}$ ) and two covered (enclosed) arms (50 cm $\times$ $40 \mathrm{~cm} \times 10 \mathrm{~cm}$ ) and the maze was elevated to a height of $50 \mathrm{~cm}$ from the floor (Parle and Singh, 2004). On the first day (i.e. $30^{\text {th }}$ day of drug treatment), each rat was placed at the end of an open arm, facing away from the central platform. Transfer latency (TL) was defined as the time (in s) taken by the animal to move from the open arm into any one of the covered arms with all its four legs. TL was recorded on the first day (training session) for each animal. The rat was allowed to explore the maze for another $2 \mathrm{~min}$ and then returned to its home cage. Retention of this learned-task (memory) was examined $24 \mathrm{~h}$ after the first day trial (i.e. $31^{\text {st }}$ day, $24 \mathrm{~h}$ after last dose). Significant reduction in TL value of retention indicated improvement in memory.

\section{Hebb-Williams maze}

Hebb-Williams maze is an incentive based exteroceptive behavioural model useful for measuring spatial working memory of rats (Parle and Singh, 2004). It consists of mainly three components. Animal chamber (or start box), which is attached to the middle chamber (or exploratory area) and a reward chamber at the other end of the maze in which the reward (food) is kept. All the three components are provided with guillotine removable doors. On the first day (i.e. $30^{\text {th }}$ day of drug treatment), the rat was placed in the animal chamber or start box and the door was opened to facilitate the entry of the animal into the next chamber. The door of start box was closed immediately after the animal moved into the next chamber so as to prevent backentry. Time taken by the animal to reach reward chamber (TRC) from start box was recorded on first day (training session) for each animal. Each animal was allowed to explore the maze for $3 \mathrm{~min}$ with all the doors opened before returning to its home cage. Retention of this learned task (memory) was examined $24 \mathrm{~h}$ after the first day trial (i.e. $31^{\text {st }}$ day, $24 \mathrm{~h}$ after last dose) (Parle et al., 2005).

\section{Statistical analysis}

All the results were expressed as Mean \pm Standard Error (S.E.M.). Data was analyzed using one-way ANOVA followed by Dunnett's $t$-test and student's unpaired t-test. $P$-values $<0.05$ were considered as statistically significant.

\section{RESULTS}

Effect on transfer latency using elevated plus-maze The young $(P<0.01)$ and aged $(P<0.05)$ rats fed with MKL $(2,4 \& 8 \% \mathrm{w} / \mathrm{w}$ of diet) showed dosedependent reduction in TL of $31^{\text {st }}$ day, indicating significant improvement of memory (Fig. 1). Scopolamine hydrobromide $(0.4 \mathrm{mg} / \mathrm{kg}$, i.p.) and diazepam $(1 \mathrm{mg} / \mathrm{kg}$, i.p.) injected before training significantly increased $(P<0.001)$ the TL indicating impairment in memory (Fig. 2). The MKL $(2,4$ \& $8 \% \mathrm{w} / \mathrm{w}$ of diet) successfully reversed memory deficits induced by scopolamine and diazepam. 


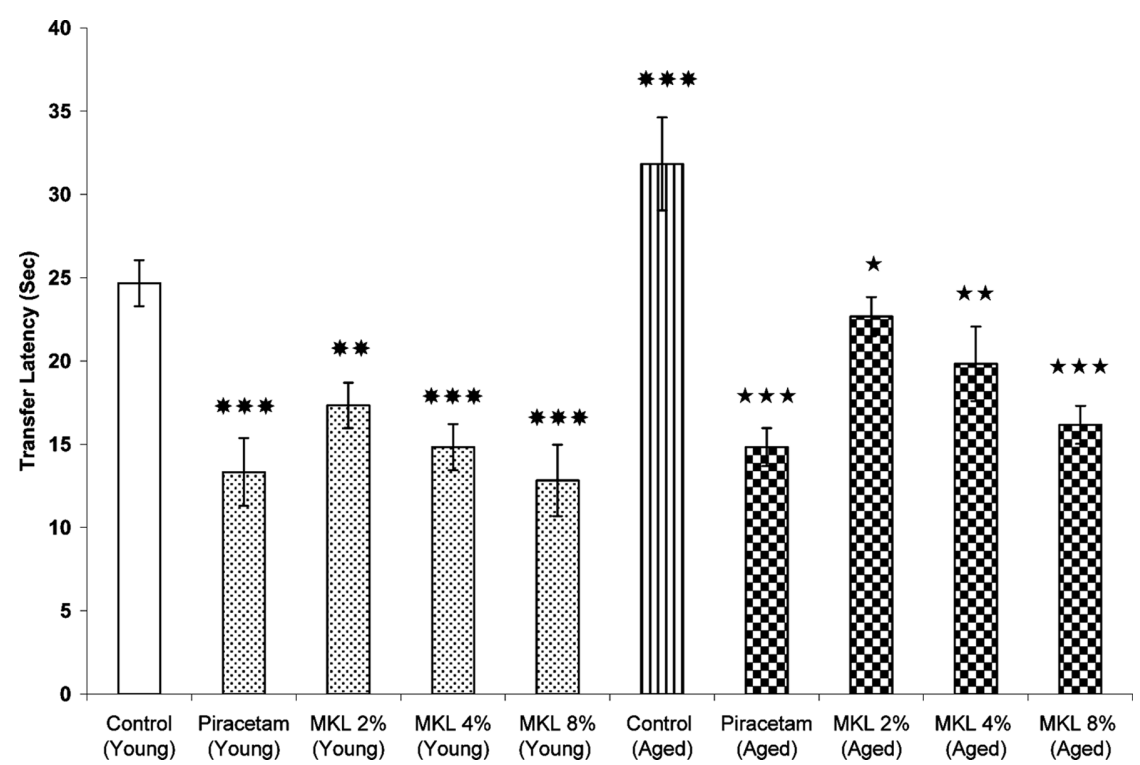

Fig. 1. Effect of various concentrations of Murraya koenigii leaves (MKL 2, 4 \& 8\% w/w of diet) on transfer latency of young (3 - 4 months) and aged (12 - 15 months) rats using elevated plus maze. Piracetam ( $400 \mathrm{mg} / \mathrm{kg}$, i.p.) was used as a positive control. Values are in mean \pm S.E.M. $(n=6)$. ${ }^{*}$ denotes $P<0.01$ as compared to control group of young rats. ${ }^{* * *}$ denotes $P<0.001$ as compared to control group of young rats. ${ }^{\star}$ denotes $P<0.05$ as compared to control group of aged rats. ${ }^{\star \star}$ denotes $P<0.01$ as compared to control group of aged rats. ${ }^{\star \star \star}$ denotes $P<0.001$ as compared to control group of aged rats. (One-way ANOVA followed by Dunnett's $t$-test and student's unpaired $t$-test).

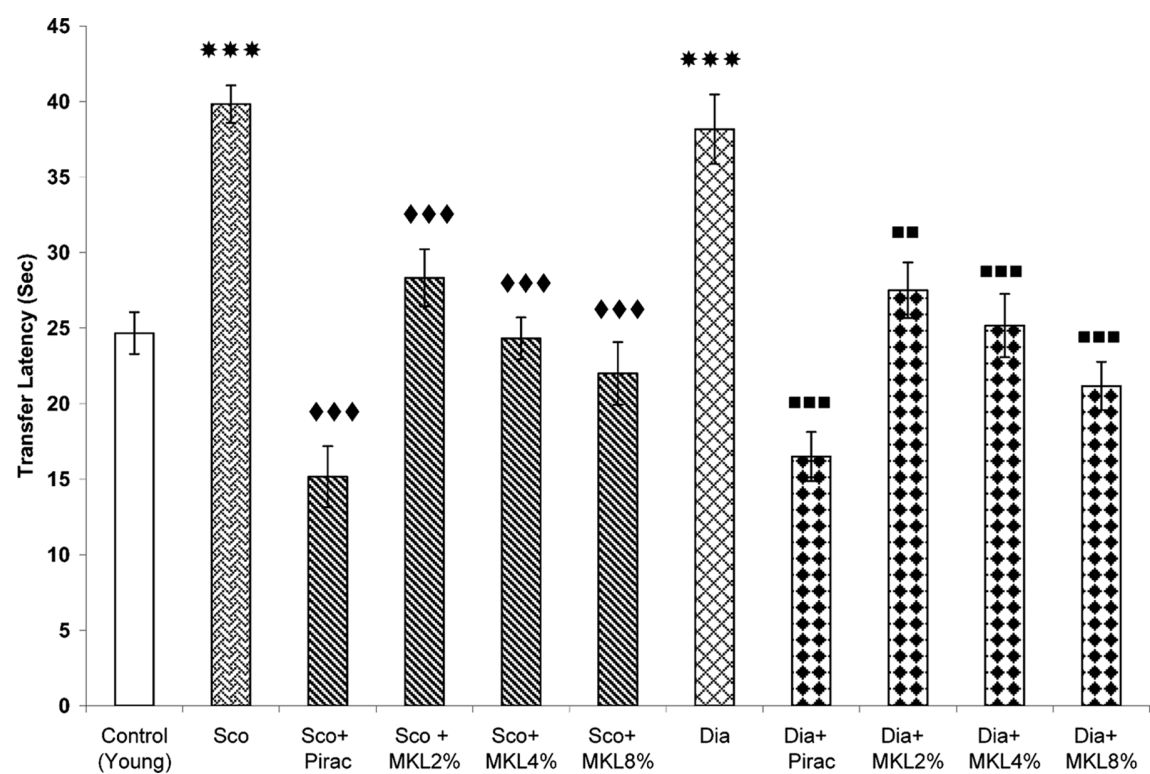

Fig. 2. Reversal of scopolamine $(0.4 \mathrm{mg} / \mathrm{kg}$, i.p.) or diazepam $(1 \mathrm{mg} / \mathrm{kg}$, i.p.) induced amnesia by Murraya koenigii leaves (MKL 2, 4 \& 8\% w/w of diet) in young rats using elevated plus maze. Piracetam (Pira) $400 \mathrm{mg} / \mathrm{kg}$, i.p. was used as a positive control. Values are in mean \pm S.E.M. $(n=6) .{ }^{* *}$ denotes $P<0.001$ as compared to control group of young rats. " denotes $P<0.001$ as compared to scopolamine (Sco) alone. ${ }^{* 1}$ denotes $P<0.01$ as compared to diazepam (Dia) alone. ${ }^{-1 e n o t e s ~} P<0.001$ as compared to diazepam (Dia) alone. (One-way ANOVA followed by Dunnett's $t$-test and student's unpaired $t$-test). 


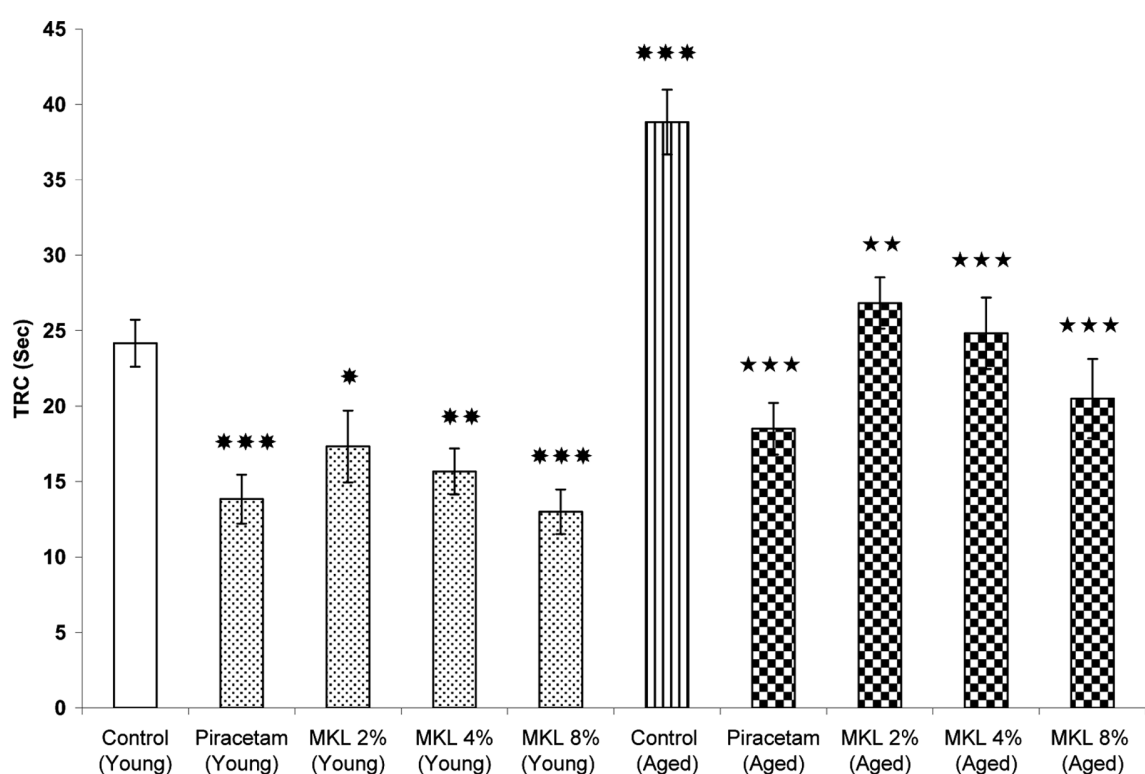

Fig. 3. Effect of various concentrations of Murraya koenigii leaves (MKL 2, 4 \& 8\% w/w of diet) on TRC of young (3 - 4 months) and aged (12 - 15 months) rats using Hebb -Williams maze. Piracetam (400 mg/kg, i.p.) was used as a positive control. Values are in mean \pm S.E.M. $(n=6)$. *denotes $P<0.05$ as compared to control group of young rats. ${ }^{* *}$ denotes $P<0.01$ as compared to control group of young rats. ${ }^{* *}$ denotes $P<0.001$ as compared to control group of young rats. ${ }^{\star \star}$ denotes $P<0.01$ as compared to control group of aged rats. ${ }^{\star \star \star}$ denotes $P<0.001$ as compared to control group of aged rats. (One-way ANOVA followed by Dunnett's $t$-test and student's unpaired $t$-test).

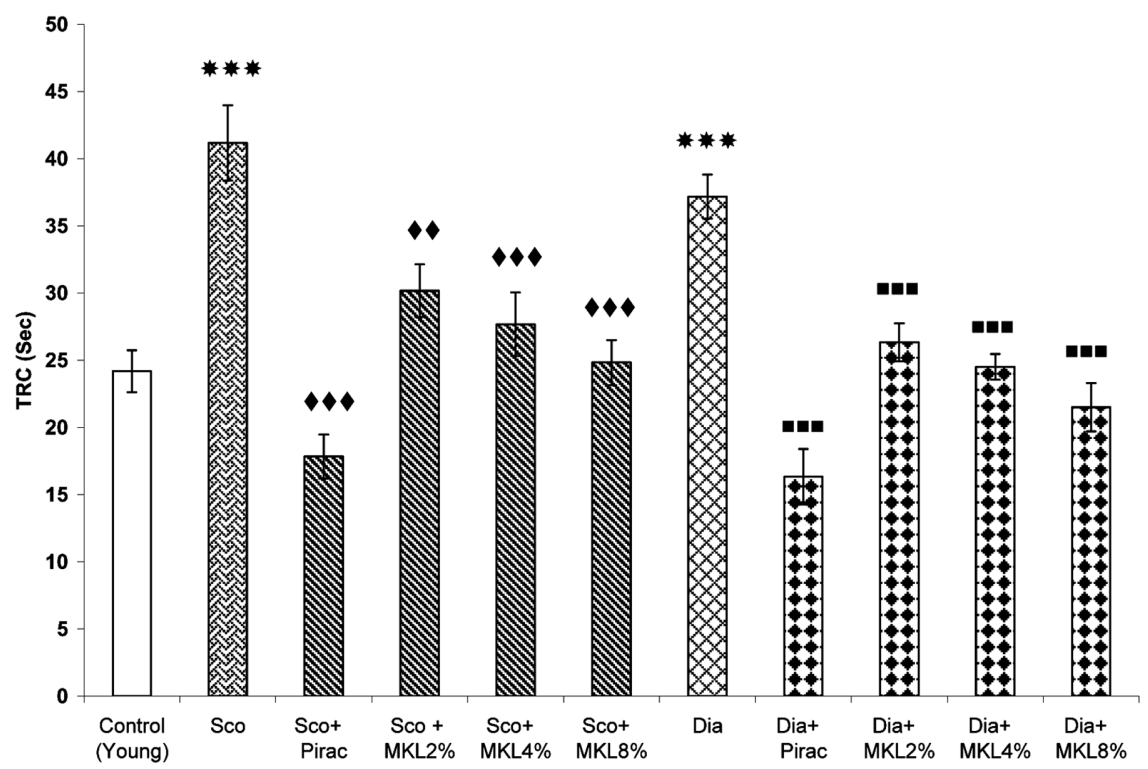

Fig. 4. Reversal of scopolamine $(0.4 \mathrm{mg} / \mathrm{kg}$, i.p.) or diazepam $(1 \mathrm{mg} / \mathrm{kg}$, i.p.) induced amnesia by Murraya koenigii leaves (MKL 2, 4 \& 8\% w/w of diet) in young rats using Hebb -Williams maze. Piracetam (Pira) $400 \mathrm{mg} / \mathrm{kg}$, i.p. was used as a positive control. Values are in mean \pm S.E.M. $(\mathrm{n}=6) .{ }^{* *}$ denotes $P<0.001$ as compared to control group of young rats. "denotes $P<0.01$ as compared to scopolamine (Sco) alone. "denotes $P<0.001$ as compared to scopolamine (Sco) alone. ${ }^{\mathbf{m}}$ denotes $P<0.01$ as compared to diazepam (Dia) alone. ${ }^{\mathbf{m}}$ denotes $P<$ 0.001 as compared to diazepam (Dia) alone. (One-way ANOVA followed by Dunnett's $t$-test and student's unpaired $t$-test). 
Piracetam (used as the positive control) at a dose of $400 \mathrm{mg} / \mathrm{kg}$, i.p. also improved memory $(P<0.001)$ in both young and aged rats and reversed the amnesia induced by scopolamine and diazepam.

\section{Effect on time taken to reach reward chamber (TRC) using Hebb -Williams maze}

MKL $(2,4 \& 8 \% \mathrm{w} / \mathrm{w}$ of diet) administered orally in young $(P<0.05)$ and aged $(P<0.01)$ rats for 30 days markedly reduced TRC as compared to the respective control groups (Fig. 3). Scopolamine (0.4 $\mathrm{mg} / \mathrm{kg}$, i.p.) and diazepam $(1 \mathrm{mg} / \mathrm{kg}$, i.p.) significantly increased $(P<0.001)$ TRC as compared to the control group of young rats, indicating impairment of memory (amnesia). MKL administered for 30 days reversed the amnesia induced by both scopolamine and diazepam (Fig. 4). The groups of rats, which were treated with piracetam $(400 \mathrm{mg} / \mathrm{kg}$, i.p.) for seven successive days showed improvement $(P<0.001)$ in memory of young as well as aged rats. Piracetam also reversed amnesia induced by scopolamine and diazepam.

\section{DISCUSSION}

Memory is one of the complex functions of the brain and ultimately involves multiple neuronal pathways and neurotransmitter systems. However, creation disorders disrupt cholinergic transmission specifically and induce dementia in affected patients (Palmer, 2002). Dementia is a mental disorder characterized by loss of intellectual ability sufficiently severe as to interfere with one's occupational or social activity. Epidemiological studies of the Indian population have revealed that dementia is largely a hidden problem. Prevalence rates for dementia increase exponentially with advancing age (Parle et al., 2004). Despite the severity and high prevalence of this disease, Allopathic system of medicine is yet to provide a satisfactory antidote. Therefore, neurobiologists all over the world are looking for new directions and alternative strategies for managing this disease. Therefore, we were motivated to explore the new approach in Indian traditional system to manage this disease. In the present study, we have focused upon exploring the potential of an Ayurvedic plant Murraya koenigii leaves in reversing the memory deficits. Rats readily accepted the specially prepared diet containing MKL. The results showed a dose-dependent $(2,4 \&$ $8 \% \mathrm{w} / \mathrm{w}$ ) diminished TL and TRC values similar to piracetam $(400 \mathrm{mg} / \mathrm{kg})$. Furthermore, pre-treatment with MKL for 30 days, similar to piracetam, protected the animals from memory deficits produced by scopolamine and diazepam. These findings suggest possible neuroprotective role for MKL.

Nootropics are a class of psychotropic agents with selective facilitatory effect on integrative functions of the central nervous system, particularly on intellectual performance, learning ability and memory capacity (Reddy and Kulkarni, 1998). Piracetam, the first representative of nootropic agents, has been shown to improve memory deficits in geriatric individuals. Repeated injection of piracetam had improved learning ability and memory capacities of laboratory animals (Bhattacharya et al., 1993).

The present study indicates that leaves of Murraya koenigii possess nootropic activity similar to piracetam in view of its facilitatory effect on retention of the learned task. MKL at all the does, enhanced retention capacity (memory) of animals in the present study. Since transfer latency was shortened on second day exposure (retention capacity) when compared to corresponding exposure TL of control group. The possibility that MKL may be anxiogenic agent rather than a memory enhancer appears to be remote in view of the fact that both, MKL and piracetam reversed scopolamine and diazepam induced amnesia. Furthermore, MKL and piracetam both consistently showed memory enhancing activity in another sensitive model like Hebb -Williams maze in the present study.

Oxidative stress, a condition of cellular prooxidantantioxidant disturbance in favor of the prooxidant state, induces the production of reactive oxygen species, leading to serious functional impairments 
such as cognitive decline (Liu et al., 2003). On the other hand, a decrease in brain peroxidation improves spatial cognition in rat model of traumatic brain injury and ethanol intoxication (Ozdemir et al., 2005). Further, increase in antioxidative activity prevents or ameliorates the impairment of memory capacity in rats produced by the infusion of amyloidpeptide into the cerebral ventricle (Hashimoto et al., 2002, 2005). Antioxidant carbazoles have been reported present in MKL may be favorably contributing to the memory enhancing effect seen in the present study. Thus, the protective effect of MKL may be attributed to its antioxidant property by virtue of which susceptible brain cells get exposed to less oxidative stress resulting in reduced brain damage and improved neuronal function (Chakrabarty et al., 1997; Ramsewak et al., 1999; Tachibana et al., 2001; Wang et al., 2003).

Further, MKL has been reported to posses antiinflammatory and hypolipidemic properties (Khan et al., 1996b; Ramsewak et al., 1999). Both of these properties may be responsible for memory-improving effect of MKL. Neurobiological evidences are highlighting a strong link between neuroinflammation at hippocampus-entorhinal cortex, cingulate gyrus and nucleus basalis magnocellularis of brain areas and impairment of memory capacities (HaussWegrzyniak et al., 1999, 2000; Marriott et al., 2002). Indomethacin, a non-steroidal anti-inflammatory drug exhibited a memory protective effect against electroconvulsive shock-induced retrograde amnesia and also against amyloid deposits in the brain (Rao et al., 2002; Stephan et al., 2003). Anti-inflammatory action of carbazole alkaloids present in Murraya koenigii leaves (Ramsewak et al., 1999) might also be contributing to the observed memory-enhancing activity of MKL in the present study. Furthermore, Murraya koenigii leaves were proved to decrease serum total cholesterol and triglycerides in rats, which may be responsible for pronounced memoryenhancing effect seen in aged rats (Khan et al., 1996b). This possibility is substantiated by the fact that high serum ratios of cholesterol precursors such as lanosterol and lathosterol (indicative of a high rate of endogenous cholesterol synthesis) were associated with relatively low memory performance in an aging human population (Teunissen et al., 2003). Combination of anti-inflammatory, antioxidant, hypolipidemic and neuroprotective role could all be leading to the net memory-enhancing effect of MKL $(2,4 \& 8 \% \mathrm{w} / \mathrm{w})$.

\section{ACKNOWLEDGEMENTS}

Authors are deeply grateful to Indian Council of Medical Research (ICMR), New Delhi, Government of India for the financial support to this study in the form of SRF. We owe a deep sense of gratitude to Dr. R. P. Bajpai, Hon'ble Vice Chancellor of Guru Jambheshwar University, Hisar for his constant encouragement and inspiration.

\section{REFERENCES}

Adebajo AC, Ayoola OF, Iwalewa EO, Akindahunsi AA, Omisore NOA, Adewunmi CO, Adenowo TK. (2006) Anti-trichomonal, biochemical and toxicological activities of methanolic extract and some carbazole alkaloids isolated from the leaves of Murraya koenigii growing in Nigeria. Phytomedicine 13, 246-254.

Adebajo AC, Olayiwola G, Verspohl JE, Iwalewa EO, Omisore NOA, Bergenthal D, Kumar V, Adesina SK. (2004) Evaluation of the ethnomedical claims of Murraya koenigii. Pharm. Bio. 42, 610-620.

Baliga MS, Jagatia GC, Rao SK, Babu SK. (2003) Evaluation on nitric oxide scavenging activity of certain spices in vitro: a preliminary study. Nahrung. 47, 261-264.

Bhattacharya SK, Upadhyay SN, Jaiswal AK. (1993) Effect of piracetam on electroshock-induced amnesia and decrease in acetyl choline in rats. Indian J. Exp. Biol. 31, 822-824.

Chakrabarty M, Nath A, Khasnobis S, Chakrabarty M, Konda Y, Harigaya K, Komiyama K. (1997) Carbazole alkaloids from Murraya koenigii. Phytochemistry 46, 751-755.

Chintawar SD, Somani RS, Kasture SV, Kasture SB. (2002) Nootropic activity of Albizzia lebbeck in mice. 
J. Ethnopharmacol. 81, 299-305.

Das KC, Chakraborty DP, Bose PK. (1965) Antifungal activity of some constituents of Murraya koenigii Spreng. Experientia 21, 340-343.

Dhingra D, Parle M, Kulkarni SK. (2003) Effect of combination of insulin with dextrose, D (-) fructose and diet on learning and memory in mice. Indian J. Pharmacol. 35, 151-156.

Hashimoto M, Hossain S, Shimada T, Sugioka K, Yamasaki H, Fujii Y, Yutaka Ishibashi Y, Oka J, Shido O. (2002) Docosahexaenoic acid provides protection from impairment of learning ability in Alzheimer's disease model rats. J. Neurochem. 81, 1084-1091.

Hashimoto M, Tanabe Y, Fujii Y, Kikuta T, Shibata $\mathrm{H}$, Shido O. (2005) Chronic administration of docosahexaenoic acid ameliorates the impairment of spatial cognition learning ability in amyloid betainfused rats. J. Nutr. 135, 549-555.

Hauss-Wegrzyniak B, Vraniak PD, Wenk GL. (1999) The effects of a novel NSAID on chronic neuroinflammation are age dependent. Neurobiol. Aging 20, 305-313.

Hauss-Wegrzyniak B, Vraniak PD, Wenk GL. (2000) LPS-induced neuroinflammatory effects do not recover with time. Neuroreport 11, 1759-1763.

Ito C, Itoigawa M, Nakao K, Murata T, Tsuboi M, Kaneda N, Furukawa H. (2006) Induction of apoptosis by carbazole alkaloids isolated from Murraya koenigii. Phytomedicine 13, 359-365.

Itoh J, Nabeshima T, Kameyama T. (1990) Utility of an elevated plus maze for evaluation of nootripics, scopolamine and electroconvulsive shock. Psychopharmacol. 101, 27-33.

Kesari AN, Gupta RK, Watal G. (2005) Hypoglycemic effects of Murraya koenigii on normal and alloxan diabetic rabbits. J. Ethnopharmacol. 97, 247-251.

Khan BA, Abraham A, Leelamma S. (1996a) Role of Murraya koenigii (curry leaf) and Brassica juncea (mustard) in lipid peroxidation. Indian J. Physiol. Pharmacol. 35, 148-150.

Khan BA, Abraham A, Leelamma S. (1996b) Biochemical response in rats to the addition of curry leaf (Murraya koenigii) and mustard seeds (Brassica juncea) to the diet. Plant Foods Hum. Nutr. 49, 295-299.

Khan BA, Abraham A, Leelamma S. (1997) Antioxidant effect of curry leaf, Murraya koenigii and mustard seeds, Brassica juncea in rats fed with high fat diet. Indian J. Exp. Biol. 35, 148-150.

Liu R, Liu IY, Bi X, Thompson RF, Doctrow SR, Malfroy B, Baudry M. (2003) Reversal of age-related learning deficits and brain oxidative stress in mice with superoxide dismutase/catalase mimetics. Proc. Natl. Acad. Sci. USA. 100, 8526-8531.

Marriott LK, Hauss-Wegrzyniak B, Benton RS, Vraniak PD, Wenk GL. (2002) Long-term estrogen therapy worsens the behavioral and neuropathological consequences of chronic brain inflammation. Behav. Neurosci. 116, 902-911.

Ozdemir D, Uysal N, Gonenc S, Acikgoz O, Sonmez A, Topcu A, Ozdemir N, Duman M, Semin I, Ozkan H. (2005) Effect of melatonin on brain oxidative damage induced by traumatic brain injury in immature rats. Physiol. Res. 54, 631-637.

Palmer AM. (2002) Pharmacotherapy for Alzheimer's disease: Progress and prospects. Trends. Pharmacol. Sci. 23, 426-427.

Parle M, Dhingra D, Kulkarni SK. (2004) Neurochemical basis of learning and memory. Indian J. Pharm. Sci. 66, 371-376.

Parle M, Dhingra D. (2003) Ascorbic acid: a promising memory-enhancer in mice. J. Pharmacol. Sci. 93, 129135.

Parle M, Singh N. (2004) Animal models for testing memory. Asia Pacific J. Pharmacol. 16, 101-120.

Parle M, Vasudevan M, Singh N. (2005) Swim everyday to keep dementia away. J. Sport Sci. Med. 4, 37-46.

Ramsewak, RS, Nair MK, Strasburg GM, Dewitt DL, Nitiss JL. (1999) Biologically active carbazole alkaloids from Murraya koenigii. J. Agr. Food Chem. 47, 444-447.

Rao SK, Andrade C, Reddy K, Madappa KN, Thyagarajan S, Chandra S. (2002) Memory protective effect of indomethacin against electroconvulsive shock-induced retrograde amnesia in rats. Biol. Psychiat. 51, 770-773.

Reddy DS, Kulkarni SK. (1998) Possible role of nitric oxide in the nootropic and antiamnesic effects of neurosteroids on aging and dizocilpine-induced learning impairment. Brain Res. 799, 215-229.

Rogers SH, Farlow MR, Doody RS, Moha R, Friedhoff LI. (1998) Donepezil study groug-A 24 week, double blind, placebo controlled trail of Donepezil ${ }^{\circledR}$ in patients with Alzheimer's disease. Neurology 50, 136. 
Stephan A, Laroche S, Davis S. (2003) Learning deficits and dysfunctional synaptic plasticity induced by aggregated amyloid deposits in the dentate gyrus are rescued by chronic treatment with indomethacin. Eur. J. Neurosci. 17, 1921-1927.

Tachibana Y, Kikuzaki H, Lajis NH, Nakatani N. (2001) Antioxidative activity of carbazoles from Murraya koenigii leaves. J. Agr. Food Chem. 49, 55895594.

Teunissen CE, De Vente J, Von Bergmann K, Bosma H, van Boxtel MP, De Bruijn C, Jolles J, Steinbusch
HW, Lutjohann D. (2003) Serum cholesterol, precursors and metabolites and cognitive performance in an aging population. Neurobiol. Aging 24, 147-155.

Wang YS, He HP, Shen YM, Hong X, Hao XJ. (2003) Two new carbazole alkaloids from Murraya koenigii. J. Nat. Prod. 66, 416-418.

Yadav S, Vats V, Dhunnoo Y, Grover JK. (2002) Hypoglycemic and antihyperglycemic activity of Murraya koenigii leaves in diabetic rats. J. Ethnopharmacol. 82, 111-116. 